Chirurg 2012 $\cdot 83: 740$

DOI 10.1007/s00104-012-2344-4

Online publiziert: 10. August 2012

(c) Springer-Verlag 2012

A. Thalheimer - C.-T. Germer

Klinik für Allgemein-, Viszeral-, Gefäß- und Kinderchirurgie, Universitätsklinikum Würzburg

\title{
Komplette pathologische Remission nach Radiochemotherapie beim Rektumkarzinom
}

\section{Metaanalyse zeigt exzellente Langzeitergebnisse}

\section{Ergebnisse}

\section{Originalpublikation}

Martin ST et al (2012) Systematic review and meta-analysis of outcomes following pathological complete response to neoadjuvant chemoradiotherapy for rectal cancer. $\mathrm{Br} \mathrm{J}$ Surg 99:918-928

Fünfzehn bis zwanzig Prozent aller Patienten mit Rektumkarzinom zeigen nach neoadjuvanter Radiochemotherapie (RChT) eine komplette pathologische Remission (pCR) im Operationspräparat. Ob dies zu einem Überlebensvorteil im Langzeitverlauf führt, ist bislang unklar.

\section{Fragestellung der Studie}

Das Ziel dieser systematischen Literaturübersicht war es, das onkologische Outcome von Patienten mit pCR nach neoadjuvanter RChT und anschließender Rektumresektion bei Rektumkarzinom zu evaluieren. Primäre Endpunkte waren hierbei Lokalrezidivrate, Fernmetastasierung, 5-Jahres-Gesamtüberleben und krankheitsfreies 5-Jahres-Überleben.

\section{Methode}

In den bekannten medizinischen Datenbanken (PubMed, MEDLINE, Cochrane Library) wurden Publikationen zum Langzeitverlauf von Patienten mit Rektumkarzinom nach neoadjuvanter RChT und anschließender Rektumresektion systematisch erfasst. Voraussetzung für die Erfassung in der Analyse waren mindestens 40 Patienten mit einem Follow-up von wenigstens 40 Monaten.
Die Einschlusskriterien wurden von insgesamt 16 Studien erfüllt. Dabei handelte es sich meist um retrospektive Analysen, nur bei 2 Studien lag ein prospektives Studiendesign vor. Insgesamt konnten die Daten von 3363 Patienten mit neoadjuvanter RChT und anschließender Rektumresektion ausgewertet werden. Dabei zeigte sich in einem Drittel ein UICCII-, in knapp zwei Drittel ein UICC-IIIRektumkarzinom. Ein sphinktererhaltendes Resektionsverfahren konnte in 73,4\% der Fälle durchgeführt werden. Für das Gesamtkollektiv fand sich eine Rate von $24,4 \%$ pCR nach neoadjuvanter RChT. $61,4 \%$ aller Patienten erhielten im weiteren Verlauf eine adjuvante Chemotherapie.

Hinsichtlich des onkologischen Verlaufs zeigte sich bei Patienten mit einer pCR eine Lokalrezidivrate von $0,7 \%$. Die Wahrscheinlichkeit des Auftretens eines Lokalrezidivs war in diesem Patientenkollektiv somit 4-mal geringer als in der Gruppe der Patienten mit inkomplettem oder fehlendem Ansprechen auf die neoadjuvante Therapie. Auch die Wahrscheinlichkeit des Auftretens von Fernmetastasen war in der pCR-Gruppe signifikant vermindert $(8,7 \%$ in der pCRGruppe). Im Hinblick auf das 5-JahresGesamtüberleben $(90,2 \%$ in der pCRGruppe) und das krankheitsfreie 5-Jahres-Überleben $(87,0 \%$ in der pCR-Gruppe) zeigte sich im pCR-Kollektiv ein signifikanter Vorteil im Vergleich zum Restkollektiv.

\author{
Diskussion und Fazit \\ des Reviewers
}

Anhand dieser Literaturübersicht wird die Bedeutung der kompletten pathologischen Remission nach neoadjuvanter RChT in Bezug auf harte onkologische Verlaufsparameter eindrucksvoll untermauert. Sowohl die Rate der Lokalrezidive als auch die Rate der Fernmetastasierung werden im Vergleich zu Patienten mit nur inkomplettem oder fehlendem Ansprechen auf die neoadjuvante RChT signifikant reduziert, das Gesamt- wie auch das krankheitsfreie 5-Jahres-Überleben deutlich verlängert. Es bleibt allerdings eine Herausforderung, die Patienten mit einer im Restaging kompletten Remission nach neoadjuvanter RChT, die auch tatsächlich eine komplette pathologische Remission haben, zu identifizieren, da hier die Notwendigkeit einer radikalen operativen Intervention zumindest angezweifelt werden kann. Auch die Tatsache, dass die Rate der Fernmetastasierung zwar reduziert, mit $8,7 \%$ aber bei weitem nicht eliminiert wird, muss in der Diskussion bezüglich der Notwendigkeit einer adjuvanten Chemotherapie in diesem Kollektiv berücksichtigt werden.

\section{Korrespondenzadresse}

Prof. Dr. C.-T. Germer

Klinik für Allgemein-, Viszeral-, Gefäß- und Kinderchirurgie, Universitätsklinikum Würzburg Oberdürrbacher Str. 6, 97080 Würzburg germer_c@chirurgie.uni-wuerzburg.de

Interessenkonflikt. Der korrespondierende Autor gibt für sich und seinen Koautor an, dass kein Interessenkonflikt besteht. 